\title{
Raised consciousness about emotions and health
}

\section{Allan Abbass*}

*Department of Psychiatry, Dalhousie University

$\mathrm{E}$ motions and their management may be one of the most relevant yet least examined issues in medicine today. Emotions are physiological events which, when mismanaged or avoided, can be somatized into adverse health and behavioral consequences in both patients and healthcare providers. High rates of somatization into various body systems and destructive health-rated behaviors lead to enormous healthcare costs, long wait lists and frustrated physicians. Recent diagnostic and treatment advances allow us to identify and manage emotional processes in a broad range of patients. Moreover, specific education about emotions may allow physicians to better self-manage in the face of an increasingly challenging professional life.

Diverse research has shown that emotions are specific physiological processes with neurobiological bases. Specific emotions have observable neurobiological patterns and somatic pathways. For example, rage, according to videotaped large case-series research, is experienced as heat that rises from the abdomen to the chest and to the arms with energy and an urge to grab or do some form of violence. However, a whole range of anxiety, somatic symptoms, and behavioral disorders may take place when such strong emotions are mobilized but obstructed. ${ }^{1}$ The neurobiological substrates, locations and functions of emotions are becoming clearer with recent neuroimage-based research. ${ }^{2}$

Research shows that when emotions are somatized or translated into somatic symptoms, health and well-being suffer. Patients with somatization frequently attend the doctor's office or Emergency department with vague distress, a broad range of somatic symptoms or the sequelae of years of selfneglect. They present at high rates with symptoms related to each bodily system including respiratory, cardiovascular, gastrointestinal, musculoskeletal, neurological and dermatological systems. ${ }^{3}$ Patients with this problem also appear to have higher overall mortality. ${ }^{4}$

The physician's response to this presentation is often biological investigations, medical treatment trials and referrals to specialists who in turn are baffled and frustrated by the problems presented. One recent study found that roughly one quarter of all specialty consultations yielded no physical diagnosis. In this study, over one third of all cardiology, neurology and gastroenterology consultations and one sixth of surgery consultations had physical symptoms without any discernable cause. ${ }^{3}$ Specialists, as second or third consultants, often feel compelled or pressured to investigate further with scans, endoscopies and other procedures, despite knowing from experience that the yield of such tests is very low. One US study found that $84 \%$ of common presentations to an internal medicine clinic yielded no diagnosis despite expensive investigations. ${ }^{5}$

Physicians and their patients, frustrated by a lack of either diagnosis or treatment, may then develop treatment misal- liance, resulting in patient complaints and even lawsuits. ${ }^{6}$ The physician, facing this and many other stresses, becomes more burned out, turning their own emotional reactions into somatic complaints, substance abuse and depression. ${ }^{7}$

The good news in this otherwise discouraging scenario is that recent education, diagnostic and treatment methods hold promise in both managing patients with somatization and arming physicians with tools to manage a challenging professional life.

Treatments that focus on emotions and how emotions are somatized have been developed to interrupt somatization and related destructive health behaviors. These treatments include Short-Term Dynamic Psychotherapy and generally result in decreased use of healthcare, medication, hospital and physician services. They result in cost savings compared to standard management when treating patients with emotion linked disorders such as irritable bowel syndrome. They also effectively treat patients with deliberate self-harm, anxiety, depression and personality disorders, all groups of patients with frequent somatic complaints and excess medical service use. $^{9}$

Intensive Short-Term Dynamic Psychotherapy, developed through videotaped research at McGill since the 1970's, has specific methods to diagnose the physiological functioning of the emotional system. With knowledge of emotion physiology and an examination procedure, one can directly detect pathophysiological processes in this system. Thus, the emotional basis of health problems may, in many cases, be detected directly as opposed to by exclusion. Symptoms are often removed or reduced during the diagnostic process itself. This emotional process alone can reduce symptoms and the need to investigate and medicate in most cases. One can directly treat the emotional factors involved in these destructive cycles. ${ }^{1}$

Education programs focusing on emotional reactions, self-awareness and personal self-management have been studied and shown to be effective. In addition, medical students involved in education programs using emotion-based videotapes, readings, preceptors, senior mentors and group discussions have been shown to have improved emotional self-awareness and well-being. ${ }^{9}$ In turn, the self-aware physician can then freely and consciously tune into emotional distress in a somatizing patient. Thus he or she may diagnose this process directly in his or her patients. As a result, he or she may prevent excess service use and complications of physical testing and treatment. The conscious physician may then recognize his patients', his colleagues', his students' and his own emotional responses. He or she can then maintain and even augment the health of both the healer and the healthcare community. ${ }^{11}$

We are in a new era in medical education. The emergence of scientific information about the human emotion system 
is changing the way we view health and health management. Perhaps some of the delay in this information reaching mainstream medicine and medical curriculum is due to the susceptibility of physicians to problems with handling emotions; this leads to blinding, various biases, shame and a tendency to burnout at unacceptable rates. ${ }^{6}$ This must be reversed through cultural change in our own ranks and support of ourselves through various modes of education.

In conclusion, new information and research about the human emotion system provides us with both a challenge and an opportunity. Since we know about the existence of specific emotion physiology and the destructive effects of ignoring pathology in this system, as a profession we must act on this information. We are pressed to be conscious of our emotional responses to those we serve and those with whom we work. Moreover, we have the primary obligation to ensure that our own personal self, as a professional vehicle, is well honed and well cared for. We have the opportunity to pass on this component of self-knowledge to colleagues and to those we teach. Finally, we have the opportunity to improve the quality of care we provide and to reduce healthcare use through early, direct diagnosis of emotion-linked health problems.

\section{References}

1. Davanloo, H. Unlocking the unconscious. Chichester: John Wiley \& Sons: 1990.
2. Phan KL, WT, Taylor SF, Liberzon I. Functional neuroanatomy of emotion: a meta-analysis of emotion activation studies in PET and fMRI. Neuroimage 2002; 16(2): 331-48.

3. Reid, S. W., T Crayford, M Hotopf. Medically unexplained symptoms in frequent attenders of secondary health care: retrospective cohort study. British Medical Journal 2001; 322(7289): 767.

4. Engel CC, L. X., Hoge C, Smith S. Multiple idiopathic physical symptoms in ECA study: competing risk analysis of 1 year incidence, mortality and resolution. American Journal of Psychiatry 2002; 159: 998-1004.

5. Kroenke K, MangelsdorffAD. Common symptoms in ambulatory care: incidence, evaluation therapy and outcome. American Journal of Medicine 1989; 86(3) 262-6.

6. Lanyon RI, A. E. Characteristics of compensable disability patients who choose to litigate. Journal of the American Academy of Psychiatry and the Law 2002; 30(3): 400-4.

7. CMA Guide to Physician Health and Well-being. Canadian Medical Association; 2003.

8. Abbass, A. The cost-effectiveness of short-term dynamic psychotherapy. Journal of Pharmacoeconomics and Outcomes Research 2003; 3(5): 535-539.

9. Novack DH, E. R., Paulsen RH. Toward creating physician-healers: fostering medical students' self-awareness, personal growth and well-being. Academic Medicine 1999; 74(5): 516-20.

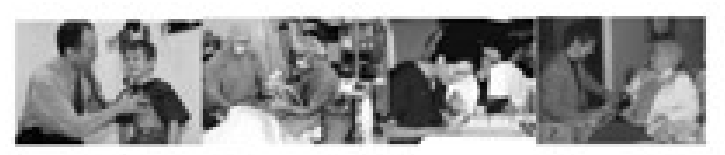

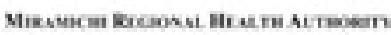
Misisestict, NB

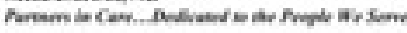

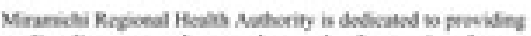

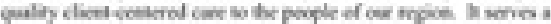

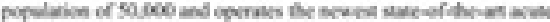

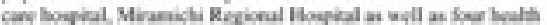

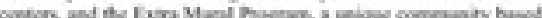
provram

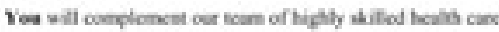
profowiceab! We wolower inquicis for be following

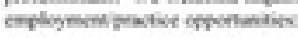

- Inoily Modicine

- Rabiollogy

* Intomul Modocine

\& Meginatrod Nime
- Spowti Lanjage Patolloyia

\& Clinical narmakist

\& Movicthoripis

\& Nudebogin

\& Molical Radiation Tectoobogin

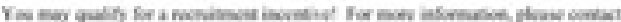

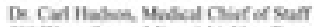

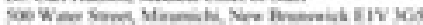

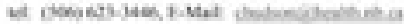

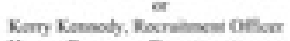

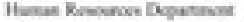

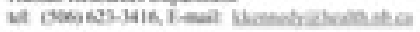

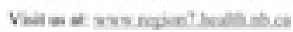

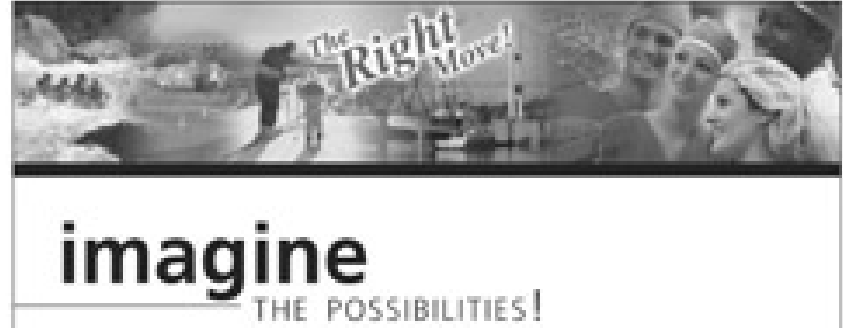

FAASER HEALTH is ceenmined is developing a pogessive nork missomem where

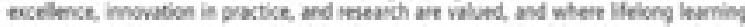

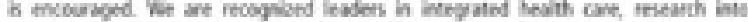

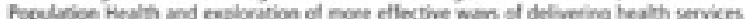

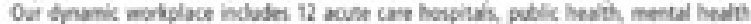
and esetinuing cart servicis.

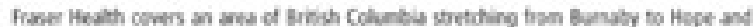

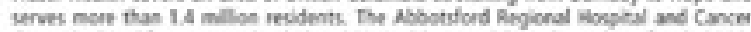
Certer is slated for construxtion in Lebe 2084. with an antopated opening of early 2006

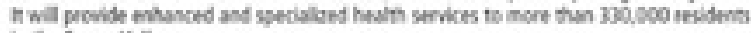
in the Foner Valley

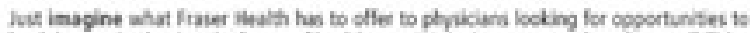

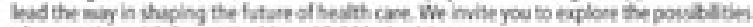
of purtrering aith iraver iteulth and 2.000 phyikim.

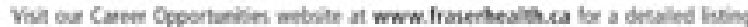

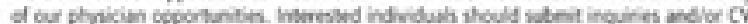

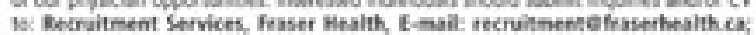
fax: (604) 575-5145.

We are ...the right move for a rewarding career! fraserhealth

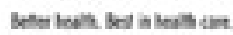


Thiak ahout practice opportunities at

The Pembede General Howpital Inc.

Now Celatrating The Openirg Of lts 546 Million Dspansice Onfering A Full Range Of Including CT. Nackar Medicine, An Expanded ER \& ICU, A New 19.Bed Acue Mental Healde Unit A New 40-Bed Medical Unit. Expanded Outpatient Rehabilitation

Services And A 22-Bed Inpatient Rehabilitatioa usit.

Curreatly Kecruiting A Variety Of Healthoare Poofessiceals.

Senpes aux possibilites de pratiqaer votre profestion a LFoital Gíntral De Pembeoktc.

LWhital oelebre ea ce moment fownerture de ses locaus elargis. doet le cour s'ékve à 36 millions de dollan.

II effre une ganme complete de services, y compris : la tomodensitometrie,

la midesine nuskaine, un Service durpence et une Uniht

de soiss inketsifs flatgik uac nouvelle Unise de witss

actifs de same meale de 19 lits, unnouveas Service de mbdicine pelnirale de to lits, de services accrus de reladapeation pour kes

persoenes en convaltation esterne et un Service de

rédretation de 22 lits dectiac aux persentes hospitalisbes.

Nous sommes petsentement a la rechenthe de drers professioeals

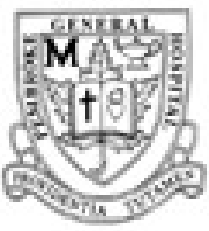

4613) 732-281 Lpre pengenhos org/www pemecnhos.org

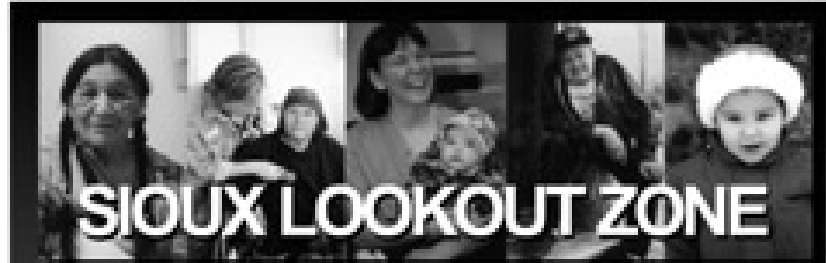

Interesting and challenging medicine in

isolated Northwestern Ontario First Nations with diverse hospital work

- Full or parteme, thocble contract arrangements

- Salary grid starts at \$212,000

- Work load os ling arerages $52 \mathrm{hrs}$ hk

- Benelts padcage, no overtiead

- 9 whs holdays 8 CME have / year

- Active teaching practice

- Dynamic supportive colleagues

- Locum tenens poetions avalable

GP/Anaesthetst opportunites

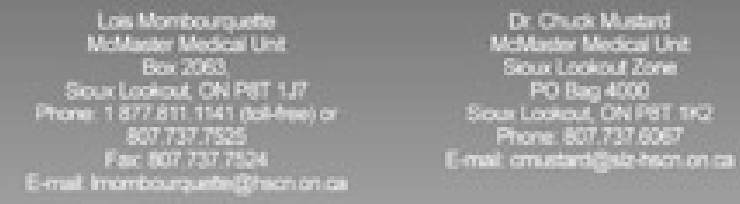

Sioux Lookout Zone ... You should be here. waw zonedocs.com

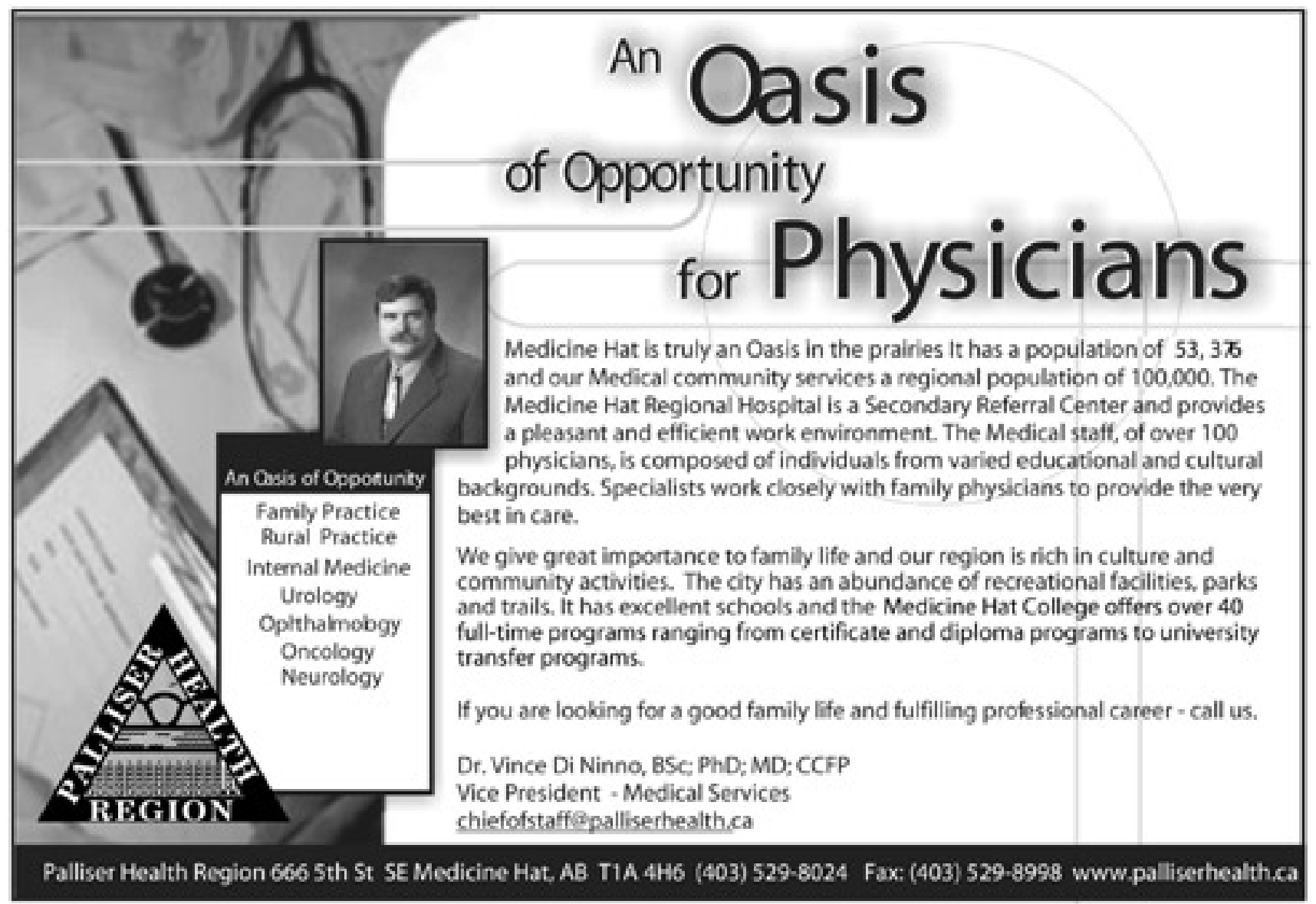

